\title{
Research on Innovative Entrepreneurship Education of Postgraduates Based on Coaching Technology
}

\author{
Ma Xiaojun ${ }^{\mathrm{a}}$, Zhang Ze, Liu Desheng, Wang Junfa, Li \\ Xiaohai, Wei Tianlu \\ College of Mechanical Engineering \\ Jiamusi University \\ Heilongjiang Province, China, 154007 \\ amjzx2009phd@163.com
}

\author{
Li Chunjiang* \\ Dean's office \\ Heilongjiang Province, China, 154007 \\ jmslcj@sohu.com
}

\begin{abstract}
The paper explains the connotation of coaching technology and provides the theoretical basis of coaching technology. Use coaching technology to explore the potential of graduate students and cultivate their innovative thinking and creative ability, so as to realize creative problem solving. At present, the domestic entrepreneurship education of postgraduates is still in the development stage. The paper explores the application of coaching technology in postgraduate innovative education, and finds a solution regarding the thinking weaknesses of postgraduates. It carries on the beneficial practice to promote the reform of postgraduate innovative entrepreneurship education and cultivate the innovation ability of postgraduates.
\end{abstract}

Keywords-postgraduate; innovation and entrepreneurship; coaching technology; implementation strategy

\section{INTRODUCTION}

As the hot spot of both theory and practice of China's higher education in recent years, the innovative entrepreneurship education comes from United States, and then reaches many countries. The 1989 International Education Conference called professional education, vocational education and entrepreneurship education as three permits of education in 21st century. China is increasing efforts to develop innovative entrepreneurship education to meet the needs of building an innovative country, enhancing our competitiveness, improving the quality of education and teaching, and easing the pressure of employment. In order to better carry out innovative entrepreneurship education, in April 2010, the general offices of Ministry of Education and Ministry of Science and Technology issued the "University Students Science and Technology Entrepreneurship Practice Base Identification Method (Trial)". In May 2010, Ministry of Education issued "Guidelines on Vigorously Promoting Colleges and Universities Innovative Entrepreneurship Education and College Students' Independent Entrepreneurship". From these we can see our country has attached great importance to this.

At present, the information is changing with each passing day, and there is no way to keep up with the footsteps of the times if we stick in the mud. Higher education in various

Fund Project: Jiamusi University degree and postgraduate education teaching reform research :(JGXM-JDY-2016011)

*Correspondence Author: Li Chunjiang(1970-),Professor, master tutor countries has been more and more inclined to innovative cultivation. As the new force and research talents in higher education, postgraduates should put more focus on cultivating their innovative consciousness and thinking. In recent years, United States, Germany, UK and other countries have all began to treat education reform and innovative personnel training as their primary goal. Their elite schools have successively opened innovative courses to mobilize the enthusiasm of students and develop their creativity. However, the innovation education in our country is still in a very weak position, especially among the postgraduate groups. The paper hopes to explore the application of coaching technology in postgraduate innovative education, and find the solution to the weak points of postgraduates' innovative thinking.

\section{ThE ORIGIN AND CONNOTATION OF COACHING TECHNOLOGY}

Coaching technology originated in sports in 1970s. It has first been popular in European and American countries. The American Timothy Gallway invented the "coaching technology" through the crash course teaching of tennis skills. After that, the deputy general manager of American AT\&T Company Archine McGill first discovered the benefits of coaching technology, and combined the coaching technology created by Timothy Gallway and business management in an innovative way, which achieved good results. In 1980s, Ericsson, Mobil, Boeing, Procter\&Gamble and other companies continued to practice the management mode of using coaching technology to inspire potential and improve efficiency, making coaching technology become popular in more and more enterprises. Coaching technology has even been widely used in university management, education, employment and various professional. Influenced by the application of western coaching technology in enterprise management, Hong Kong University of Science and Technology, Zhongshan University, Fudan University and other domestic colleges and universities have launched related training and speeches successively. Coaching technology is gradually being incorporated into the teaching plan. In 2006, Tsinghua University applied coaching technology in its employment guidance and career planning education. 


\section{THE THEORETICAL BASIS OF COACHING TECHNOLOGY}

\section{A. People-oriented, Self-awareness, Stimulating the Potential}

The purpose of the coaching technology is "peopleoriented" and "teaching students in accordance of their aptitude". Through guidance, encouragement and other means, it improves coaches' self-development awareness, identification motives and goals, and their mental model, and stimulates their potential. Achieve a reasonable career planning by improving their self-learning, planning, problem-solving skills, helping them explore the basic path to solve the problem. "People-oriented" means to respect the individual's own choice and thinking, not exceeding one's authority and letting coach make decisions for postgraduates; it means to trust their ability to solve problems, and stimulate the potential of postgraduates through coach's demonstration, guidance and scene substitution, let them take positive actions to realize the dream; it's not knowledge infusion, the passive way of "teaching" students a variety of abilities.

\section{B. Integration of Resources, Systematic Teaching}

Students' career and entrepreneurship education are not only related to the employment of students, but also related to the growth of students, national stability and long-term development. As a practical, open and social education mode, coaching technology is in urgent need of promotion. But the specific implementation process still needs to integrate various resources, including schools, employers and government resources, and let all units participate in student entrepreneurship guidance courses teaching together. It not only involves multidisciplinary fields, but also involves multiple units. We need to have an open mind and absorb the advantages of all parties, and participate in the reform of entrepreneurship education model together.

\section{The Transplant of Coaching Technology}

Because of the differences in culture, national conditions and talent needs, we must refer to our country's higher education system, the reality of students and schools, and gradually form the educational concept, system and practice with Chinese characteristics. Improve the professional quality and skills of college students, and set reasonable career development goals. Combine employment guidance and innovative entrepreneurship education, so as to better play the professional and efficient role of coaching technology. Therefore, the promotion of application of coaching technology in innovative entrepreneurship education is of great significance to the reform of curriculum education, growth of young students and sustainable development of economy.

\section{The VAlue of InNOVATIVE ENTREPRENEURSHIP EDUCATION OF POSTGRADUATES BASED ON COACHING TECHNOLOGY}

Coaching technology is a technology that improves the minds of coaches, helps them to tap their potential, improve innovative thinking ability and organizational creativity, so that they can achieve their own transcendence and creatively solve problems. Coaching technology focuses on guiding and stimulating. As modern human resource management theories which can effectively stimulate people's potential and improve their work performance, it is widely used in university management, education, employment and various professional. Explore the promotion of coaching technology to innovative entrepreneurship education, and carry out pioneering experiments to promote college students career planning and employment guidance education reform, develop innovative talents and extend the organizational creativity of postgraduates.

\section{A. Enhance the Self-confidence and Psychological Quality of Postgraduates, and Maintain Their Mental Health}

With the rapid development of science and technology and increasingly fierce competition, high-quality innovative entrepreneurship talents training become an important task of innovative country construction. There are both prospect and risk when starting businesses. It is a major task of university education that how to guide students to correctly deal with the risks and setbacks encountered in the process of starting businesses, and help them ease pressure, adjust emotion and maintain a healthy mental state. Innovative entrepreneurship education in colleges and universities not only takes the initiative to create a good environment of innovative entrepreneurship for students, but also needs to pay attention to learning guidance and potential stimulating, improving students' quality in all aspects.

\section{B. Mobilize the Enthusiasm of Postgraduates to Participate in Entrepreneurship, and Improve the Efficiency of Entrepreneurship Education Counseling Activities}

Currently, there are very few college postgraduates choosing to start a business, and its success rate is also very low. Although the society becomes more and more concerned about entrepreneurship, the enthusiasm of students are likely to be affected because of lack of entrepreneurial knowledge and thinking, and experience, weak risk resistance and financing difficulties. Through coaching technology, students can change their attitude and simplify problems, which is conducive to mobilizing their enthusiasm of entrepreneurship. In addition, the fact that coaching technology focuses on guidance, rather than blindly indoctrination, makes the "people-oriented" thinking easier for students to accept. Let students find the cause more quickly through divergent questions, and come up with solutions, greatly improving the efficiency of entrepreneurship education counseling activities.

\section{THE IMPLEMENTATION STRATEGY OF INNOVATIVE ENTREPRENEURSHIP EDUCATION OF POSTGRADUATES BASED ON COACHING TECHNOLOGY}

Coaches need to diverge coaches' thinking space, and explore their own resources by focusing on "what I have". Evaluate the advantages of coaches on expertise, character, skills, knowledge and interpersonal communication. The recognition of others will let postgraduates feel strong and warm and enhance their self-confidence, so as to stimulate their potential and find feasible path in an innovative way. Find truth, blind spots and potentials by asking neutral and enlightening questions, and then come up with solutions. Or guide postgraduates to sum up their successful experience to improve their self-sight and let them see more possibilities. Help 
postgraduates analyze their attributional tendencies, guide them to attribute success to ability, effort, mood and other controllable factors, and attribute failure to not working hard enough, rather than uncontrollable factors. Learn to adjust the mood in a calm and effective way. Let coaches really understand their mental model, and learn to adjust their attitude, correctly identify the situation, remove the dross and absorb useful information, creating a solution to the problem in the best state.

\section{A. Create a Good Coaching Relationship, and Assess Coaching Content}

Firstly, create an open and trusting relationship. Postgraduates need to express their expectation towards coach through communication. At the same time, the coach needs to concern about the inner voice of postgraduates and learn the truth, rather than focusing on the superficial information and answer. Coach should find postgraduates' mental mode through their speech and deportment, and respond accordingly, forming a trusting relationship. Make both sides a good impression through the expression of gratitude.

Secondly, the coach should help postgraduates identify their needs and targets by focusing on "what do you want, and how to know what you want" like a compass. If you do not know what your goal is, you will never find the right direction, and your efforts will be wasted eventually. Through directional and continuous questioning, coach enables coaches to select the target in a most effective way, and let them wake from the chaotic state and start self-planning and self-management.

Thirdly, the coach should reflect coaches' beliefs, emotions and behaviors in an actual way, so that coaches can know their position, face up to real problems, and find blind spots, so as to know the inner interference and the gap between status quo and goals, as well as the possible affects. At the same time, the coach needs to strengthen their beliefs, and adjust coaches' negative attitude to positive side at any case. The coach should stimulate couches' greatest potential, encourage them to make the most effective choice and work down to earth to do everything well, so as enhance their learning motivation.

\section{B. Develop a Coaching Plan, Integrate Resources, and Implement Actions}

The coach should help postgraduate plan goals and make plans, and determine the achieving time, implement them into daily life and refine them to every action. When postgraduates see the difference between reality and ideal through the coach, they will naturally make appropriate adjustments. Some people's success is not invariable. The coach will ask coaches to make practical plans according to their own needs, and adjust the strategy according to the actual situation in the implementation process. Tap their potential, challenge them and find new possibilities, at the same time expand thinking and seek for development and innovation, so as to be able to meet the challenges of future society. People who have a strong desire for success will work harder and more positively, and play to the score. Such people will work with perseverance until they succeed.

\section{Finish Coaching, and Track Feedback}

In the coaching process, we should give timely feedback; make response and adjustment to changes. After finishing the coaching, we need to check whether the expected goal is reached or not. Communicate with each other, and share summary. If necessary, we can track the later effects.

\section{CONCLUSION}

The application value of coaching technology in postgraduate innovative entrepreneurship education lies in the change of thinking mode. Its idea of explaining problems let postgraduates believe they have the resources, potential and energy to solve the problem, helping people find the solution to the problem themselves. This positive perspective has important significance in mobilizing students' positive initiative on self-learning and self-developing, stimulating their greatest potential and transforming the teaching concept of traditional employment guidance course. It should be noted that the coach should know how to manage the expectations of visitors when providing service for visitors after evaluating their quality. Coaches need to have a wealth of career experience or entrepreneurial experience. They not only need to understand the law of talent development and student characteristics, but also need to have a positive attitude and good character to have a positive impact on the students in a subtle way. On the other hand, to really play the role of coaching technology, we need to combine different disciplines, professional characteristics and talent needs, have multi-participatory coordination, and conduct transplantation, thus enhancing the effectiveness of educational activities. With the advancement of teaching reform in colleges and universities, it is particularly urgent to take the new element of coaching technology into the university education research. Currently, there are still many problems to be solved in the application of coaching technology in Chinese college entrepreneurship education, such as the development of coaching courses and lack of coaches. Therefore, further research is needed to promote sustainable development of the project.

\section{REFERENCES}

[1] Zhou Jianwen, Tang Yujie. Research on Innovative Entrepreneurship Education and Practical Teaching Mode of "Coach Training"- Taking Jiangxi Vocational College of Mechanical \& Electrical Technology as an Example[J]. Vocational Education Forum, 2016, (14): 59-62. (In Chinese)

[2] Xu Haiyan, Zheng Qingliang, Zhang Zhixiong.Study on the Cultivation of Postgraduates' Innovative and Enterprising Ability Based on the Platform of Science and Technology Festival - Taking "Zhonghaichuang Cup" Postgraduates Science and Technology Festival of School of Electrical Engineering and Automation, Fuzhou University as an Example [J]. Innovation and Entrepreneurship Education, 2015, (03): 100-103. (In Chinese)

[3] Jie Pingying. Exploration of Coach-based Vocational College Coaching Instructor System[J]. China Vocational and Technical Education, 2014, (15): 47-51. (In Chinese)

[4] Shangxiao Ye. Application of Coaching Technology to Cultivate Graduate Students' Innovative Thinking[D]. Capital University of Economics and Trade, 2014. (In Chinese)

[5] Fu Jiang. Cultivate Innovative Entrepreneurial Spirit, And Explore Postgraduates Business Team[J]. Business, 2013, (23): 82. (In Chinese) 
[6] Li Tao, Sheng Wenbin, Sun Xia. Innovation-based Postgraduate Technology Entrepreneurship Education Research[J]. China Adult Education, 2012, (13): 75-78. (In Chinese)

[7] Zeng Linghua.Study on Talent Training Model Based on Coaching Technology [J] .Enterprise Vitality, 2010, (08): 73-77. (In Chinese)

[8] Wang Shuo. Research On Innovative Talents Development Of Master Graduate Students[D]. Capital University of Economics and Trade, 2008. (In Chinese)
[9] Wu Yan. Domestic Coaching Technology Development Status and Training Effect Migration Research [D]. Shanghai Normal University, 2008. (In Chinese)

[10] Liu Miaoling. Humanistic Management And Enterprise Coaching Technology [D]. Jinan University, 2004.(In Chinese) 